\title{
Una interpretación del tacto activo a partir del estudio morfológico del test de Rorschach y su adaptación desde la perspectiva de la educación inclusiva*
}

\author{
An Interpretation of the Active Touch based on the Morphological Study of the Rorschach Test and its Adaptation \\ under the Perspective of Education \\ Uma interpretação do tato ativo a partir do estudo morfológico do teste de Rorschach e sua adaptação desde a \\ perspectiva do ensino inclusivo
}

\author{
Maria del Pilar Correa Silva ${ }^{\text {a }}$ \\ Universidad Tecnológica Metropolitana, Chile \\ pcorrea@utem.cl \\ ORCID: http://orcid.org/0000-0003-4074-5472
}

DOI: https://doi.org/10.11144/Javeriana.syp38-75.itae

Fecha de recepción: 28 Agosto 2018

Fecha de aprobación: 20 Abril 2019

Fecha de publicación: 15 Noviembre 2019

\section{Resumen:}

El presente artículo expone el proceso de adaptación del test de Rorschach a una modalidad táctil. Se busca precisar y confirmar si una persona con ceguera tiene la posibilidad de reconocer y localizar las apercepciones descritas por terceros, a partir de patrones visotáctiles, mediante la corporización de las características morfológicas que se encuentran en las manchas de tinta del test. Esta investigación aplicada utilizó una matriz de análisis basada en la semiótica peirciana para identificar y confirmar la posibilidad de sustituir los diferentes elementos morfológicos constituyentes del signo plástico: textura, color y contorno, y llevarlos a una versión táctil. Los resultados demostraron la posibilidad del cambio de formato representacional para el reconocimiento de los atractores y atrapar, desde otra modalidad sensorial, los qualia como representaciones mentales de las cualidades perceptuales e interpretativas de las manchas del test y constituirse como una propuesta de material para la enseñanza inclusiva.

Palabras clave: test de Rorschach, educación inclusiva, percepción táctil, ceguera, signo plástico.

\section{Abstract:}

This article outlines the process of adapting the Rorschach test as a tactile modality. It intends to confirm and pinpoint whether a blind person is able to recognize and locate aperceptions described by third parties, based on visual-tactile patterns, through the embodiment of the morphological features found in the ink spots in the test. This applied research used an analysis matrix based on the Peircean semiotics to identify and confirm the possibility to substitute the different morphological elements constituting the plastic sign: texture, color and contour, and putting them in a tactile version. The results showed the possibility to change the representational format for the recognition of the atractors and to catch, under a different sensory modality, the qualia as mental representations of the perceptual and interpretative qualities of the spots. It will be considered as a material proposal for the inclusive education.

Keywords: Rorschach test, inclusive education, tactile perception, blindness, plastic sign.

\section{Resumo:}

O presente artigo expõe o processo de adaptação do teste de Rorschach a uma modalidade tátil. Visa precisar e confirmar si uma pessoa com cegueira tem a possibilidade de reconhecer e localizar as apercepções descritas por terceiros, a partir de padrões visotáteis, mediante a corporização das caraterísticas morfológicas encontradas nas manchas de tinta do teste. Esta pesquisa aplicada utilizou uma matriz de análise baseada na semiótica peirciana para identificar e confirmar a possibilidade de substituir os diferentes elementos morfológicos constituintes do sinal plástico: textura, cor e contorno, e os levar para uma versão tátil. Os resultados demonstraram a possibilidade de alterar o formato representacional para o reconhecimento dos atratores e atrapalhar, desde outra modalidade sensorial, os qualia como representações mentais das qualidades perceptuais e interpretativas das manchas do teste e constituir-se como proposta de material para um ensino inclusivo.

Palavras-chave: teste de Rorschach, educação inclusiva, percepção tátil, cegueira, sinal plástico.

Notas de autor:

${ }^{a}$ Autora de correspondencia. Correo electrónico: pcorrea@utem.cl 


\section{Introducción}

El presente trabajo se desarrolla a partir de la premisa de que la "educación es un derecho humano fundamental", y que cada persona deber estar en igualdad de condiciones de aprovechar las oportunidades educativas ofrecidas para satisfacer sus necesidades básicas de aprendizaje, tal como se indica en la Declaración Universal de Derechos Humanos de la Unesco (diciembre de 1948) y en la Declaración Mundial de Educación para Todos (aprobada en Jomtien, Tailandia, en 1990). Sin embargo, contrasta con este pensamiento el hecho de que es en la educación superior donde las personas con discapacidad tienen menor presencia. Estudios de alcance internacional arrojan que, en la formación universitaria, las vivencias de los estudiantes en situación de discapacidad no siempre han sido positivas, presentándose como una de las instituciones educativas más excluyentes para su acceso y permanencia (Moriña Díez y Perera Rodríguez, 2016, p. 599).

Sobre la misma temática, otras investigaciones concluyen, considerando distintas realidades, que entre las principales dificultades para la inclusión en la educación superior, se encuentra la poca existencia o la franca carencia de materiales e instrumentos apropiados para la docencia. En la mayoría de los casos, estos recursos no han pasado por adecuaciones curriculares o adaptaciones pedagógicas para los estudiantes en situación de discapacidad, de modo que estos puedan cursar con éxito sus asignaturas y terminar su formación profesional. En países como Botwana, Costa Rica y Chile, esta problemática ya ha quedado identificada en las aulas universitarias, entre otras dificultades (Chiny, Salas y Vargas, 2008; Moswela y Mukhopadhyay, 2011; Salinas Alarcón, Lissi, Medrano Polizzi, Zuzulich Pavez y Hojas Loret, 2013). También se ha comprobado que dicha situación no varía sustancialmente en otros países con mayor cantidad de recursos, como los mencionados en un estudio realizado en 2011 en la Universidad de Sevilla, específicamente en la Facultad de Ciencias de la Educación, Psicología y Filosofía, en el cual queda de manifiesto que una de las dificultades que enfrentan sus estudiantes con discapacidad es el acceso a los contenidos y la adaptación de materiales (Moriña Díez y Cotán, 2011). En este contexto, se hace necesario ofrecer herramientas apropiadas para derribar las barreras y promover la inclusión efectiva (Lissi et al., 2013).

En el caso de las personas con discapacidad visual, estas han debido enfrentar barreras crecientes, lo que encuentra una de sus explicaciones en la historia de la cultura occidental, donde se le ha otorgado una fuerte primacía a la visión, sobre los demás sentidos y fuentes perceptuales. Para confirmar esto, basta recordar que desde Platón hasta Descartes fue considerada como «el más noble de los sentidos» (Jay, 1993/2007, p. 25).

Por otro lado, al incursionar en el espacio "no visual" en el que habitan los sujetos con discapacidad visual, observamos que el «ver» no es una facultad que dependa de la luz, sino de los objetos. De tal descubrimiento se originó la certeza de que el acto de "ver" no es exclusivo de la percepción visual, sino que: "El cuerpo en su conjunto acude al fenómeno de «ver», donde la percepción es acción corporizada que recoge información espacial de los objetos del mundo y la interpreta” (Correa Silva, 2011, p. 202).

A esto podemos agregar que el uso de material didáctico en la educación de los niños ciegos, ha permitido que diversos estudios como los realizado por Edman (1992), Kennedy (2005), Claudet, Theurel, Witt, Hatwell y Gentaz (2013), entre otros, lleguen a conclusiones altamente pertinentes, semejantes a la aportada por Rosa “[...] los ciegos disponen de un sistema de representación mental de características equiparables al de los videntes, y cuyas peculiaridades, sin duda muy numerosas, habría que estudiar con detenimiento, pero que les permite manipular figurativamente la realidad que les circunda [...]” (1980, p. 63).

Estas características han sido evidenciadas en diversos estudios y sin embargo aún queda mucho camino por recorrer, especialmente en la actualidad. Efectivamente, en nuestros días, el foco no se dirige a las carencias biológicas de las personas en situación de discapacidad, sino en las oportunidades y particularidades de los entornos y productos diseñados para superar las barreras que limitan el acceso de estas a los distintos ámbitos del compartir, sean estos sociales, culturales, educativos, recreativos, etc. Este cambio de enfoque, desde lo biológico a lo sociocultural, hace emerger lo que se conoce como "Diseño para todos", "Diseño Universal" o 
"Diseño Inclusivo". Hoy, este tipo de interpretación y práctica disciplinar se ha transformado en un parámetro inexcusable. Eugenia Vanoni (2006, p. 61) sostiene que la discapacidad ya no puede ser pensada como algo que le ocurre al otro, sino que nos interpela y conmina a la reformulación del paradigma actual.

\section{El signo táctil figurativo}

Esta investigación avanzó sobre la construcción teórica y la realización de proyectos aplicados en torno al reconocimiento del existir tangible de las imágenes. Sin embargo, tanto la investigación como el desarrollo de material concreto han privilegiado la representación figurativa y su gran capacidad para transmitir los rasgos morfológicos y visoespaciales de los objetos que pueblan el mundo. Hasta ahora, el trabajo realizado permite corroborar la capacidad interpretativa del tacto activo que, junto a las cualidades topológicas de los objetos, facultan a la persona ciega para acceder al mundo de las imágenes figurativas, a partir del reconocimiento de sus referentes identitarios y la experiencia acumulada. Dicha habilidad generalmente está vinculada con las imágenes con un alto grado de iconicidad, donde la imagen táctil mantiene una analogía con la realidad, como parte de la experiencia de los "espacios vividos".

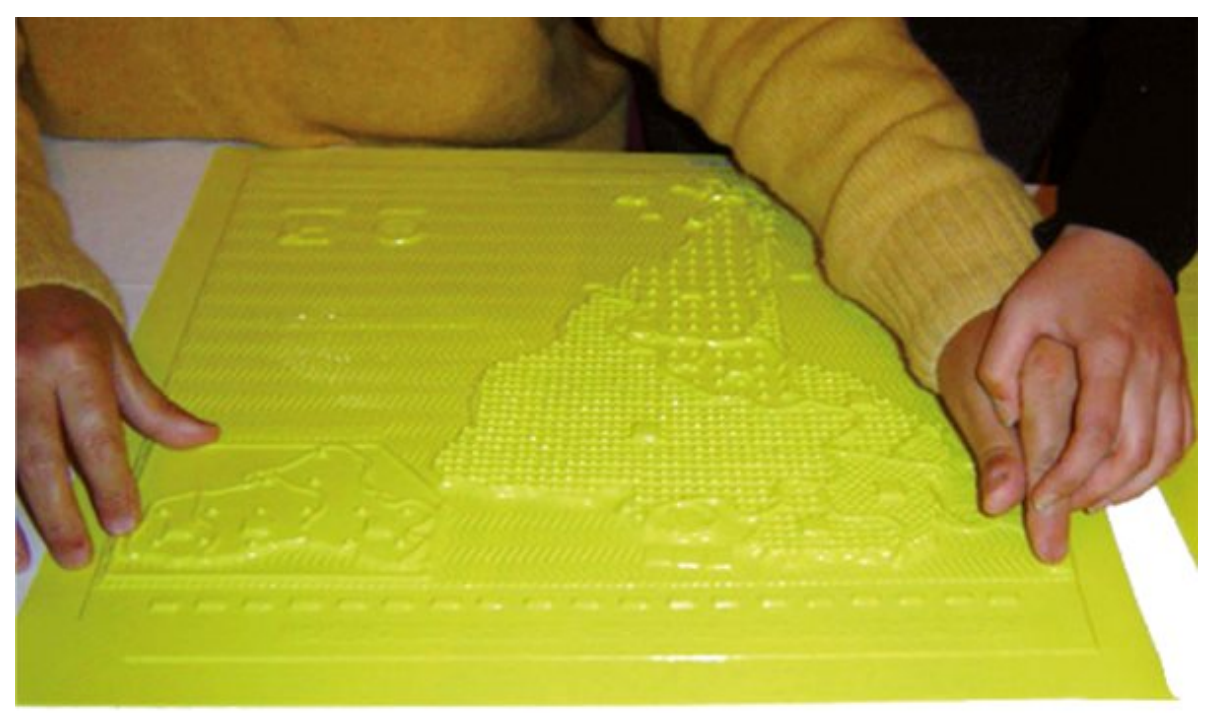

FIGURA 1

Plano táctil de densidad de la población América del Sur, realizado en proyecto OEA 2005. CECAT Santiago de Chile 


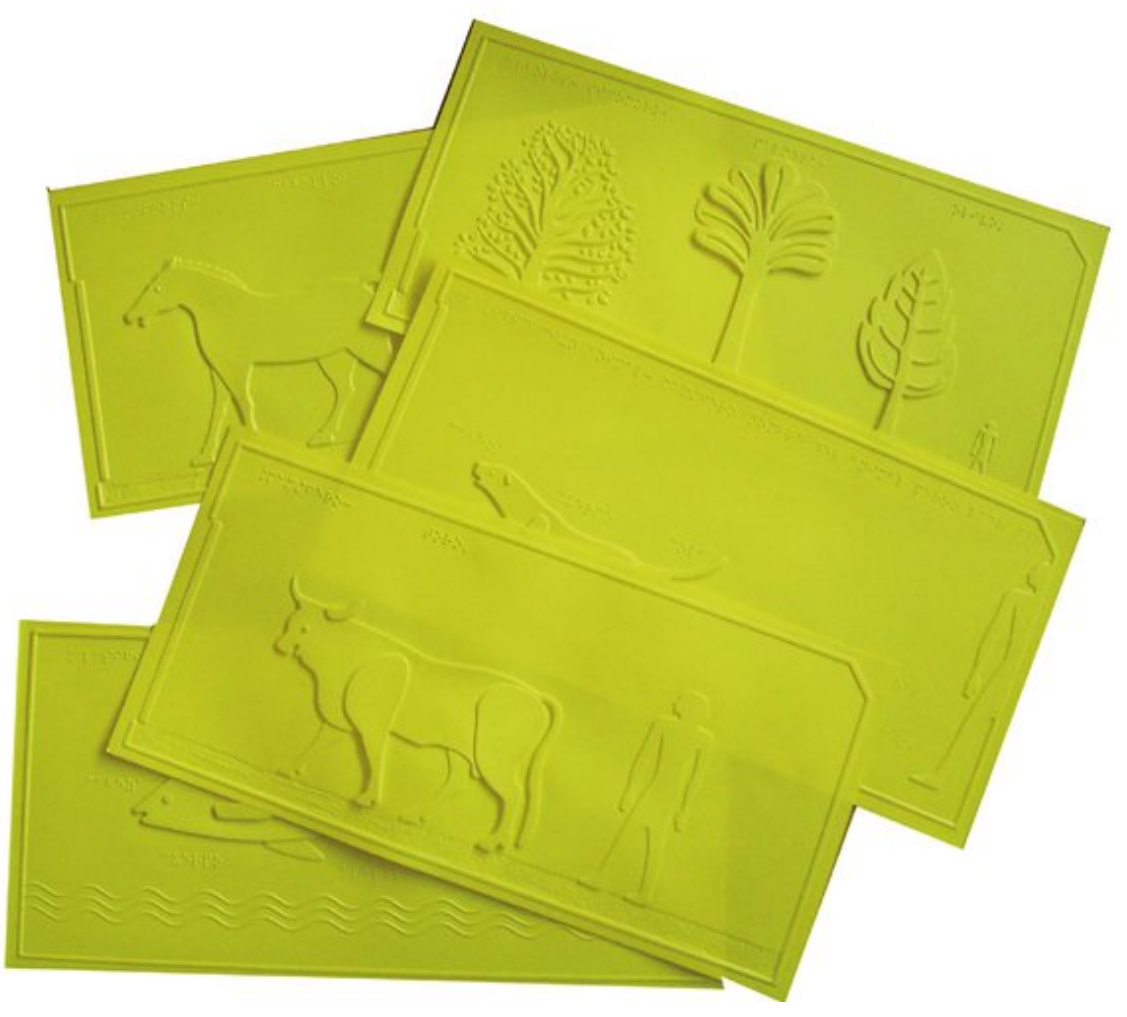

FIGURA 2

Imágenes táctiles: Estudio morfológico con base en el canon egipcio Fuente: Correa Silva (2011)

El propósito de este estudio, como el de la producción de material táctil para personas ciegas y de baja visión que se realiza en el Centro de Cartografía Táctil (CECAT), de la Universidad Tecnológica Metropolitana (figuras 1 y 2), ha sido acercar la cultura visual a las personas con ceguera. Antes de avanzar sobre este punto, es importante distinguir algunos de los resultados obtenidos en investigaciones anteriores, en las cuales ha quedado de manifiesto el poder de las formas y los contornos, como límites para ser apreciados por la acción de la mano. En esta primera fase, que podemos denominar hermenéutica, contribuyeron especialmente autores clásicos, los que destacaron la importancia del tacto y la percepción háptica en el fenómeno del ver y del conocer (Gibson, 1950/1974; Katz, 1930; Revèsz, 1950) y otros más contemporáneos, como David Marr (1982/1985), quien desde las ciencias abocadas al estudio de la inteligencia artificial planteara la siguiente afirmación: "El poder y la vivacidad con que los contornos pueden representar la forma no está en duda" [The power nd vividness with which contours can depict shape is not in doubt] (Marr, 1982/1985, p. 216). Este fenómeno también se da en la percepción háptica de patrones bidimensionales por las personas con ceguera, tanto con la percepción de los contornos como de las superficies (Ballesteros, Bardisa y Reales, 2005; Eriksson, 1999; Heller, 2000; Kennedy, 2005). En consecuencia y a través de estos autores, se ha corroborado que los contornos y las superficies son propiedades muy relevantes de la forma, como así también la textura de carácter óptico-táctil, que en conjunto permiten acercarse al fenómeno de la visión a través de las manos (Claudet et al., 2013).

En la actualidad y gracias al avance de las tecnologías, se han acrecentado las aplicaciones de las imágenes táctiles tanto en el mundo editorial como en otros ámbitos objetuales, pero aún no se ha producido mayor reflexión sobre el existir de las imágenes táctiles como signos. El estado del arte sigue siendo generoso en lo concerniente a la imagen visual, mientras los avances en torno al existir epistémico de la imagen táctil siguen concentrados en las investigaciones sobre la discapacidad visual. A diferencia de lo anterior, el presente estudio sigue una línea epistemológica que se enfoca principalmente en las propiedades de la imagen como signo y de 
las capacidades cognitivas de la percepción táctil, siendo este el modelo de análisis preliminar para el nuevo arquetipo de la imagen no figurativa que se busca.

Hasta ahora se ha propuesto una semiótica para la imagen táctil como signo motivado por su similitud respecto al objeto, al tener este la particularidad de transmitir los parecidos y de representar la realidad (Correa Silva, 2011, p. 275). Estos estudios son la base conceptual y productiva sobre la cual se sustenta esta nueva investigación, que busca comprender de modo especial el proceso de reconocimiento de una imagen que no tiene un objeto de referencia conocido por parte del perceptor con ceguera (manchas Test de Rorschach).

Entre las fuentes teóricas más relevantes se encuentran estudios desde la ciencia cognitiva y la neurociencia computacional, que buscaron explicar la cognición teniendo como modelo para sus estudios el sistema visual, en otras palabras, intentaban explicar los fenómenos perceptuales y sus interrelaciones con el ambiente. Entre dichos estudios se encuentran: el enfoque integrado de la percepción del mundo visual que hiciera hace ya muchos años J. Gibson (1974) y el mecanismo del procesamiento de la información visual propuesto por D. Marr (1982/1985). Este último fue el que, a partir de los tres niveles propuestos para el procesamiento de la información visual, permitió formular una metodología para el procesamiento digital y conceptual de la imagen figurativa en relieve, a través del cual se genera la matriz para la reproducción de las imágenes táctiles y la representación del modelo tridimensional (Correa Silva, 2011, p. 267). Esta metodología se ha recogido e implementado en la producción de todas las imágenes táctiles que se realizan para los textos de estudio, entregada a los niños y niñas con ceguera del país desde el año 2007, por parte del Gobierno de Chile. En esta misma línea, en el año 2011, se realizó una investigación con apoyo de la Comisión Nacional de Investigación Científica y Tecnológica (CONICYT, Chile), que tuvo como uno de sus objetivos comprobar si la modalidad háptica, como sistema sensorial y motor, podía ser un recurso válido para acercar las representaciones visuales utilizadas en los textos educativos en las aulas del país, a los niños con ceguera.

Por otro lado, las teorías del conocimiento con enfoque biológico de Maturana y Varela (1984) aportaron los fundamentos del porqué las representaciones táctiles, serían para algunas personas un acoplamiento estructural de su contextura biológica con el medio natural y social. Esto se entrelaza y refuerza con los postulados de la perspectiva sociohistórica de Vygotski, que valora el sistema social implantado en los espacios creados por los hombres, y la perspectiva histórica desarrollada como la derivada natural de los seres vivos. Lo que en buenas cuentas propone Vygotski (2000) es lo que él llama una mediación instrumental, la que constituiría los apoyos externos que permiten al hombre mediar el estímulo, esto es, representarlo en otro lugar o en otras condiciones.

En el caso de las discapacidades sensoriales, como la discapacidad visual, sus mayores barreras están en la recogida de información del entorno, y de los medios culturales que utilizan las representaciones visuales. Para las personas con ceguera, estas mediaciones en relieve son apoyos indispensables para la interpretación del mundo vivido a través del sentido del tacto.

\section{El Test de Rorschach y su configuración espacial}

Al llegar a este punto, queremos introducir nuestra inquietud por examinar el caso del test de Rorschach, como objeto de estudio de una posible semiótica táctil para las imágenes no figurativas, y como tal, velar por cumplir con la serie de atributos que las caractericen como signo táctil. En este propósito, junto con explorar la posible sustitución de los constructos físicos que permitan la manipulación sensoriomotriz de las formas, está el comprender cómo una persona con ceguera puede acceder a interpretar signos abstractos como, en este caso, las manchas de dicho test.

Las manchas del Rorschach pertenecen al mundo de la abstracción, al ámbito de las imágenes plásticas que fueron configuradas para ser percibidas exclusivamente por la vista, y que buscan a través de formas abstractas, arbitrarias y simétricas estimular la evocación visual de otras imágenes. Pensar que eventualmente también 
podrían ser percibidas por el tacto, aprovechando los aspectos espaciales que la constituyen, y comunicar sus características morfológicas a un perceptor con ceguera, nos lleva a indagar acerca de su pertinencia más allá del mundo de la percepción visual y de las ciencias psicológicas en el cual comúnmente se les conoce.

Podemos añadir que sus formas también han sido aprovechadas, entre otros, por artistas como Andy Warhol, en la serie "Rorschach's paintings" de 1984, lo que de alguna manera nos anima a destacar aún más esta particularidad plástica de naturaleza espacial. Sobre todo nos lleva a develar, desde este espacio epistemológico, las razones por las cuales un estudiante ciego las puede percibir, reconociendo e identificando con su tacto los bordes y, eventualmente, algunos elementos del interior de la figura delimitada, permitiéndole finalmente asociar la forma de la imagen mental que el intérprete de las manchas visuales describe.

También se puede decir que estas manchas podrían, en su individualidad, describirse como ejercicios de arte, y observar en ellas lo que, en el año 1934, Henri Focillon divulgó respecto a una de las características comunes a toda composición artística "El espacio es su ámbito [...] el espacio intervenido por una técnica que se define como materia y como movimiento. La obra de arte es ponderación del espacio, es forma: esto es lo que debemos considerar antes que nada" (Focillon, 2010, p. 12).

Es así como al observar la manera en que cada una de las manchas del test, los pigmentos, se apropia de un determinado espacio del soporte de papel blanco, y siguiendo, las palabras del mismo autor, se puede entender por qué en la exterioridad de la mancha se encuentra su principio interno. Y en la medición y cualificación del espacio, se identifica su forma: “[...] ahí está, ante nuestros ojos y en nuestras manos” (Focillon, 2010, p. 13). Es esta propiedad visoespacial de las manchas la que permite que se puedan configurar, para ser también reconocidas e interpretadas a través del sentido del tacto.

Es así como el test con sus diez manchas de tinta parece responder a una espacialidad singular. Sus formas únicas, sus contornos con bordes definidos y superficies con texturas visoespaciales, con una clara distinción entre la forma y el fondo, se orienta, como todo ejercicio de arte "[...] hacia lo único afirmándose como un todo, como un absoluto; al mismo tiempo, pertenece a un complejo sistema de relaciones" (Focillon, 2010, p. 11). Relaciones que son esenciales para el reconocimiento del todo a partir de las partes. Relaciones que involucran la orientación de cada mancha, su tamaño respecto al fondo, su eje de simetría que le confieren una identidad y una lectura diferente según se presenten al perceptor.

Estas propiedades visoespaciales de las manchas del Rorscharch que pertenecen al mundo de la abstracción, son imágenes plásticas que fueron configuradas para ser percibidas por la vista. No obstante, por los aspectos que la constituyen, en especial por sus características morfológicas, también pueden ser percibidas por el tacto: "Su valor semiótico consiste en recuperar la actividad mental identificatoria llevada a cabo por el intérprete, tal como se evidencia al delimitar determinadas zonas de las correspondientes láminas y marcarlas como configuradoras de la imagen cuya presencia afirma” (Magariños de Morentin, 2008, p. 205).

\section{Signo plástico táctil: una iconicidad espacial por recorrer}

En el contexto actual de la educación inclusiva, el aprendizaje y aplicación del test de Rorschach se ha transformado en una barrera, al ser su carácter solo visual. A partir del supuesto que también puede pasar a constituirse como signo táctil de una semiótica sustituyente, este estudio se avocó al análisis del signo plástico en particular, y se sustenta, como ya se expuso, en los estudios ya presentados sobre el signo figurativo táctil con base en el modelo propuesto por Peirce (1974). El valor de este trabajo se concentra en el análisis de la sustitución de las entidades cualitativas y configuracionales de la existencia del signo con cualidades visuales, para su posterior valorización como un signo plástico táctil, que hace énfasis en sus particularidades morfológicas y en las capacidades interpretativas de su perceptor.

En este contexto, es fundamental el Tratado del signo visual escrito por el Grupo $\mu$ el año 1993, el cual se orienta con especial esmero a la semiótica de la imagen, y permite, desde el estudio de la imagen 
visual, proyectar otro existir corpóreo afín a la descripción, que nos faculte aislar, segmentar o estratificar sus componentes, para posteriormente recomponer y volver a modelizarla para otra forma de ser percibida. El Grupo $\mu$ afirma que los signos plásticos también se asocian a un plano del contenido y a un plano de la expresión, y que: "Un enunciado plástico puede ser examinado desde el punto de vista de las formas, de los colores, de las texturas y, además desde el conjunto formado por los unos y por los otros” (Grupo $\mu, 1993$, p. 170). Este enfoque permite separar el análisis del fenómeno. En primer lugar, el foco deberá colocarse en el plano de la expresión, y en seguida en el plano del contenido, para luego volver a generar una unidad significativa, que posibilite una interpretación con las codificaciones que ya han sido ampliamente difundidas y catalogadas. Desde esta perspectiva, es pertinente recordar la definición de perceptema de Bense y Walther, donde se establece que en la relación signo-medio actúa la "materialidad", en la relación signo-objeto la "forma" y en la relación signo-interpretante, su conexo (1975, p. 30).

Magariños de Morentin (2008) a partir de sus estudios del signo visual basados en la teoría y modelo tríadico de Pierce y las relaciones constituyentes del signo, propone configurar diversas semióticas posibles. Estas investigaciones, basadas también en el modelo visual de la imagen, pueden brindar el sustento teórico y procedimental para descomponer, analizar y volver a componer nuestro objeto de estudio para una experiencia sensorial diferente (tabla 1). En su trabajo sobre el campo de la semiótica, el autor desarrolló una serie de propuestas en torno a las múltiples semióticas o, como él las llamó, Mundos Semióticos Posibles (MSPs); en este ámbito, se trabajó en busca de una semiótica particular.

Las manchas del test de Rorschach son imágenes visuales plásticas, y como propuesta perceptual, interpretada exclusivamente por sus componentes cualitativos de color, textura y forma, se clasifica como un cualisigno ico\#nico (Magariños de Morentin, 2008, p. 181). A partir de esta categorización como signo y distinguiendo sus cualidades morfológicas, se podrá hacer una aproximación a la descomposición que permita identificar sus relaciones semiótico-cognitivas posibles para constituirse como signo táctil. A continuación, se presenta el modelo propuesto por Magariños para aproximarse a una definición de signo, en este caso, basándose en una percepción visual y trabajando en paralelo los 9 canales constituyentes de su estructura, para la valoración del perceptor. (tabla 1 ). 
TABLA 1

$\mathrm{La}(\mathrm{s})$ semiótica(s) de la imagen visual

\begin{tabular}{|c|c|c|c|c|}
\hline$\overline{3}$ & $\begin{array}{l}\text { I } \\
\text { (En alguna relación) } \\
\text { Considerada como } \\
\text { representación }\end{array}$ & $\begin{array}{l}1 \\
\text { Entidades consitutivas } \\
\text { para 1: cualisignos; } \\
\text { para 2: sinsignos; } \\
\text { para 3: legisignos }\end{array}$ & $\begin{array}{l}2 \\
\text { Imagen material visual } \\
\text { 1: plastica; } \\
\text { 2: figurativa; } \\
\text { 3: conceptual; } \\
\text { 4: por convinatoria de los } \\
\text { anteriores (modos posibles } \\
\text { de presentación) }\end{array}$ & $\begin{array}{l}3 \\
\text { Selección perceptual en } \\
\text { posibles sistemas } \\
\text { para 1: cualidades; } \\
\text { para 2: existentes; } \\
\text { para 3: normas } \\
\text { Identificación }\end{array}$ \\
\hline 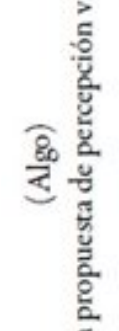 & $\begin{array}{l}\text { II } \\
\text { (Por algo) } \\
\text { Destinada a la } \\
\text { configuración de una } \\
\text { forma }\end{array}$ & $\begin{array}{l}4 \\
\text { Componentes analítico- } \\
\text { constructivos } \\
\text { para 1: qualia; } \\
\text { para 2: contornos de } \\
\text { oclusión, ejes o marcas; } \\
\text { para 3: estructura de } \\
\text { sostén y morfologia }\end{array}$ & $\begin{array}{l}5 \\
\text { Atractor } \\
\text { para 1: atractivo; } \\
\text { para 2: existencial; } \\
\text { para 3: simbólico }\end{array}$ & $\begin{array}{l}6 \\
\text { Agrupamientos hacia } \\
\text { el interior; } \\
\text { el exterior }\end{array}$ \\
\hline$\stackrel{\tilde{E}}{5}$ & $\begin{array}{l}\text { III } \\
\text { (Para alguien) } \\
\text { Para su valoración }\end{array}$ & $\begin{array}{l}7 \\
\text { Actualización del efecto } \\
\text { de sentido } \\
\text { para 1: semiótica plástica; } \\
\text { para 2: semiótica } \\
\text { figurativa; } \\
\text { para 3: semiótica } \\
\text { conceptual }\end{array}$ & $\begin{array}{l}8 \\
\text { Mostración } \\
\text { para 1: de carencia; } \\
\text { para 2: de semejanza o } \\
\text { diferencia; } \\
\text { para 3: del lugar del sistema }\end{array}$ & $\begin{array}{l}9 \\
\text { Interrelación posible: con } \\
\text { todas y cualquiera de las } \\
\text { semiosis sociales } \\
\text { efectivamente vigentes }\end{array}$ \\
\hline
\end{tabular}

Fuente: Magariños de Morentin (2008, p. 179)

Nota. Modelo propuesto por Magariños para una definición de signo basada en percepción visual y trabajando los nueve canales constituyentes de su estructura para valoración del perceptor.

\section{Planteamiento metodológico}

Es importante señalar que esta es una investigación aplicada, con orientación cualitativa, basada en el Método de Diseño Centrado en el Usuario (User Centered Design [UCD]). En nuestro estudio el modelo semiótico propuesto para el test de Rorschach en sobrerrelieve se ajustó, en distintas etapas, a las necesidades y requerimientos expresados por quienes van a ser los usuarios finales de este instrumento de medición, en este caso estudiantes con ceguera en el contexto de aprendizaje de la educación superior. Al comenzar la indagación, de modo exploratorio, se formuló de manera preliminar la siguiente interrogante: ¿Cómo los estudiantes con ceguera podrían valerse de sus capacidades táctiles, para la percepción y aprehensión de los patrones de las diez manchas de tinta visuales? Esto con el fin de alcanzar una comprensión de la problemática y la identificación de los factores involucrados. Los datos se obtuvieron principalmente por medio de entrevistas focalizadas a dos informantes claves del ámbito investigado: un estudiante con ceguera y un especialista. Ambos pertenecientes a la carrera de Psicología de una universidad de Santiago de Chile y participantes de la cátedra que tiene como objetivo orientar a los estudiantes en la aplicación e interpretación de las principales técnicas proyectivas. A partir de este procedimiento, se obtuvo el primer prototipo del set de láminas adaptado en relieve.

Luego, con los prototipos de las láminas táctiles, se desarrolló una primera etapa de validación más experimental y de carácter colaborativo. Se realizó un primer focus group con estudiantes de psicología con discapacidad visual. En esta oportunidad, se estructuró la recogida de información considerando la conformación del fenómeno en estudio, como signo táctil, en su dimensión representativa. Se utilizaron 
técnicas cualitativas, especialmente la de grupos focales. El objetivo principal fue determinar el grado de recepción de las características topológicas de las formas y los umbrales mínimos de discriminación en la relación signo-medio, con el fin de valorar el papel protagónico y los requerimientos de los estudiantes en situación de discapacidad, para la adaptación de las variables físicas invariantes de las manchas.

El trabajo con el segundo grupo focal tuvo el propósito de ajustar las características formales de los atractores, de cada una de las manchas, valorando en este caso la relación que debe darse entre signo-objeto, o sea su fundamento. Ambos grupos participaban del Programa para la Inclusión de Alumnos con Necesidades Especiales (PIANE) de la Universidad Católica.

Por las particularidades funcionales de nuestro usuario y el tipo de interfaz por evaluar, se optó por realizar la recogida de datos en grupos de trabajo, tipo focus groups, y las técnicas de evaluación seleccionadas fueron el método del "pensamiento en voz alta" y la de observación. De este modo se procuró pesquisar las descripciones, características y atributos de las gráficas en relieve desde dos miradas diferentes: la del sujeto en su contexto de uso y la del experto en el registro visual del proceso. La técnica promueve a los usuarios que piensen en voz alta mientras trabajan con la interfaz. Nielsen y Loranger (2006) plantearon que en las distintas evaluaciones de usabilidad se debe buscar el énfasis en descubrir lo que realmente hace el usuario. La aplicación de esta técnica a usuarios ciegos permitió priorizar el canal de comunicación más desarrollado por ellos, el verbal, y motivar la interacción entre los diferentes participantes.

Por otra parte, el focus group con los especialistas buscó obtener las características precisas del conjunto de formas y la organización de cada mancha. De este modo, el perceptor ciego, con el auxilio de una representación táctil y con los atractores potenciados, podría recuperar y establecer las asociaciones con las zonas que son portadoras de significados, y que a su vez se corresponden con las categorizaciones que han sido establecidas en los códigos de tabulación de este test. Se utilizó como instrumento de recogida de información el Protocolo de Localización Rorschach, de forma que los especialistas realizarán sus aportes en forma gráfica y escrita directamente en el atractor-contorno de cada mancha.

La segunda etapa de valorización buscó constatar que la relación signo-interpretante fuera practicable en los entornos académicos con estudiantes en situación de discapacidad. Dicha etapa contó con la participación, en calidad de coinvestigadora, de Pilar Calderón Albornoz, Magíster en Pedagogía Universitaria, Licenciada en Educación Superior y Psicóloga. Su desarrollo incluyó también la participación de cuatro expertos, a los cuales se consultó por el aporte de esta modalidad del test, y posteriormente el test táctil fue sometido a un proceso de ajuste realizado por 16 especialistas psicometristas, provenientes de siete universidades de Santiago de Chile. La actividad se realizó en cuatro grupos focales en los cuales también participaron estudiantes de la Universidad Central. En esta oportunidad, se evaluaron la calidad y pertinencia de los datos sensoriales en la localización de la imagen ya codificada y la interpretación de las posibles respuestas potenciales del test. En esta etapa, se buscó consolidar un modelo de representación en relieve, distinguiendo las capacidades multisensoriales en la recogida de información visual. El resumen de esta actividad se presenta en la tabla 2. 
TABLA 2

Etapas de validación y los participantes en cada una de ellas

\begin{tabular}{|c|c|c|c|}
\hline & Jueces & Material & Categorias de análisis \\
\hline \multirow{12}{*}{ 总 } & 5 estudiantes de & Aplicación piloto de las & - Discriminación: altura del borde \\
\hline & psicología con & láminas táctiles con la & - Línea continua/discontinua \\
\hline & ceguera $y / o$ & técnica de observación & - Rigurosidad de la textura (alta, media, baja) \\
\hline & discapacidad visual & & - Tamaño \\
\hline & severa. Programa & & \\
\hline & PIANE-UC & & \\
\hline & 6 especialistas & Análisis de las láminas & - Propiedades determinantes de los estímulos \\
\hline & psicometristas & táctiles y protocolo de & - Principales características atractoras \\
\hline & docentes. & localización Rorschach & - Ejes de simetría \\
\hline & Programa PIANE- & & - Localización de la mancha en relación con el observador \\
\hline & UC & & - Discriminación del número de lámina \\
\hline & & & - Relación textura-color \\
\hline \multirow{10}{*}{ 古 } & 4 especialistas & Análisis del prototipo & - Análisis de la forma como determinante de la codificación \\
\hline & & mejorado y protocolo de & (interna y externa) \\
\hline & & localización Rorschach & - Evaluación del atractor (global y en detalle) \\
\hline & & & - Figura/fondo (espacios blancos) \\
\hline & & & - Color como determinante de lectura \\
\hline & 16 especialistas & Aplicación del prototipo & - Análisis de los procesos cognitivos perceptivos \\
\hline & docentes & mejorado con protocolo de & - Localización \\
\hline & $\begin{array}{l}\text { universitarios; } 15 \\
\text { alumnos }\end{array}$ & localización Rorschach & $\begin{array}{l}\text { - Totalidad y partes de la mancha (respuesta global o de } \\
\text { detalle) }\end{array}$ \\
\hline & & & - Significación de los espacios en blanco \\
\hline & & & - Importancia de la detección de las zonas de color originarias \\
\hline
\end{tabular}

Fuente: elaboración propia

\section{Procedimiento}

En la etapa previa a la validación, se digitalizaron a 72 dpi las 10 manchas del test de Rorschach. La resolución baja es debida a las diferencias de discriminación entre la percepción visual y táctil; luego se realizó el análisis formal de cada una de ellas. En segundo lugar, las cinco manchas que incorporan color en su configuración se convirtieron a escala de grises, para posteriormente ser representados en relieve. La variable color no es una propiedad sensible al tacto. Posteriormente, se realizó, a través de un software con formato de mapa de bits, la detección de bordes con una precisión de cuatro pixeles.

A partir del patrón obtenido se realizaron dos tipos de imágenes táctiles (figura 3). En una de ellas se valorizó la variable de la textura como conformadora de la imagen a través de las diferencias de relieve (A), respondiendo en este caso más a un enfoque microsemiótico. La segunda imagen se desarrolló con base en la variable de la forma, conformada por contornos oclusivos y una superficie homogénea (B), entendible como un concepto-límite, o como lo define el Grupo $\mu$ : "forma-envoltorio" (Grupo $\mu, 1993$, p. 30). En esta forma con relieve la figura se evidencia por un solo nivel sobresaliente del fondo, y en consecuencia responde más a un enfoque macrosemiótico (Grupo $\mu, 1993$, p. 42). En este caso, las manchas con color fueron trabajadas en diferentes niveles de altura para diferenciar esta variable (de $1 \mathrm{~mm}$ a $3 \mathrm{~mm}$ ).

Estos dos tipos de representaciones sobre la base de las cualidades visotáctiles de las manchas, requirieron técnicas diferentes de reproducción en relieve, por lo que la primera validación consistió en seleccionar el modo de reproducción de la imagen táctil. Ambos enfoques se ven representados en la figura 3. 


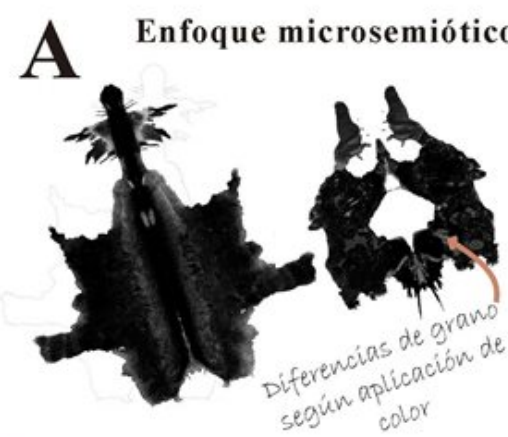

Imagen en mapa de bit con borde realzado. Énfasis en la textura

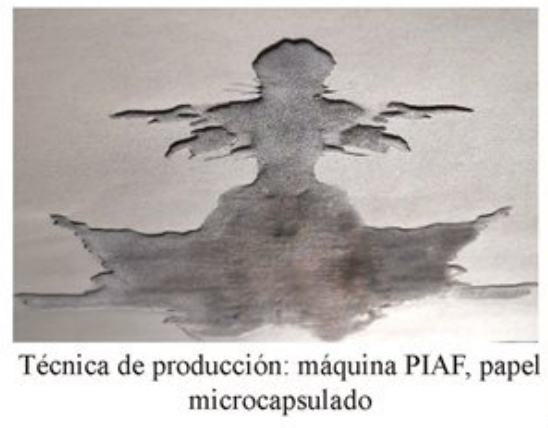

B Enfoque macrosemiótico

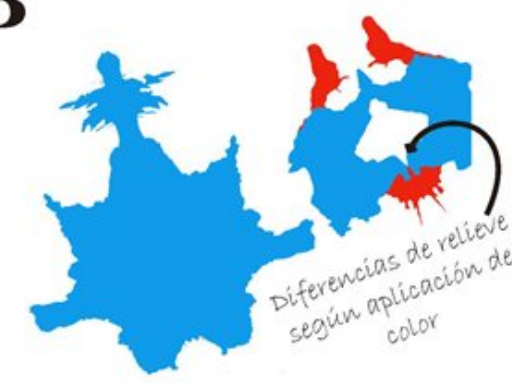

Imagen vectorial con realce en la Figura/ fondo. Énfasis en la forma.

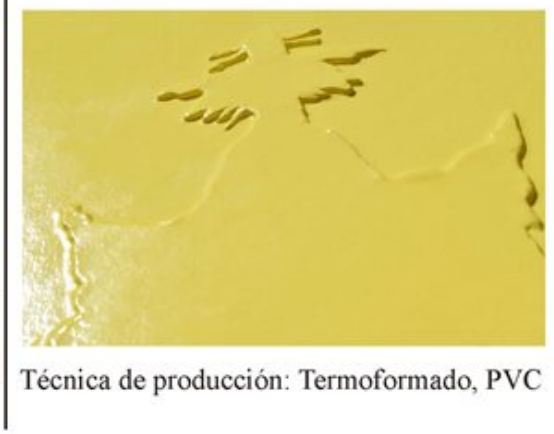

FIGURA 3

Tipos de reproducciones posibles en base a las cualidades viso-táctiles de las manchas Fuente: elaboración propia

Durante esta etapa de la investigación, se realizaron diferentes prototipos para validar la mejor técnica de reproducción. La muestra que dio mejores resultados es la que pone en valor la textura y el modo de producción que se realiza a través la máquina PIAF, también llamada horno fuser. Se reconoce que este es un sistema práctico para la elaboración de gráficas táctiles, dado que su cualidad más relevante es la de entregar imágenes en sobrerrelieve, en pocos instantes. De esta cualidad se desprende su nombre, ya que PIAF corresponde a las siglas en inglés de "pictures in a flash" (P.I.A.F.), lo que se puede traducir como "imágenes en un instante" o "imágenes en un momento". En el caso de estudio, su principal aporte a la investigación desarrollada es el resultado que se logró en las gráficas, especialmente, el tratamiento sutil de diferencias de nivel y la gradación de texturas que se pueden percibir en las manchas del test, características que se lograron por los diferentes niveles de brillo en la impresión. En la figura 4 se explícita el proceso de validación del Rorschach táctil, en dos etapas. 


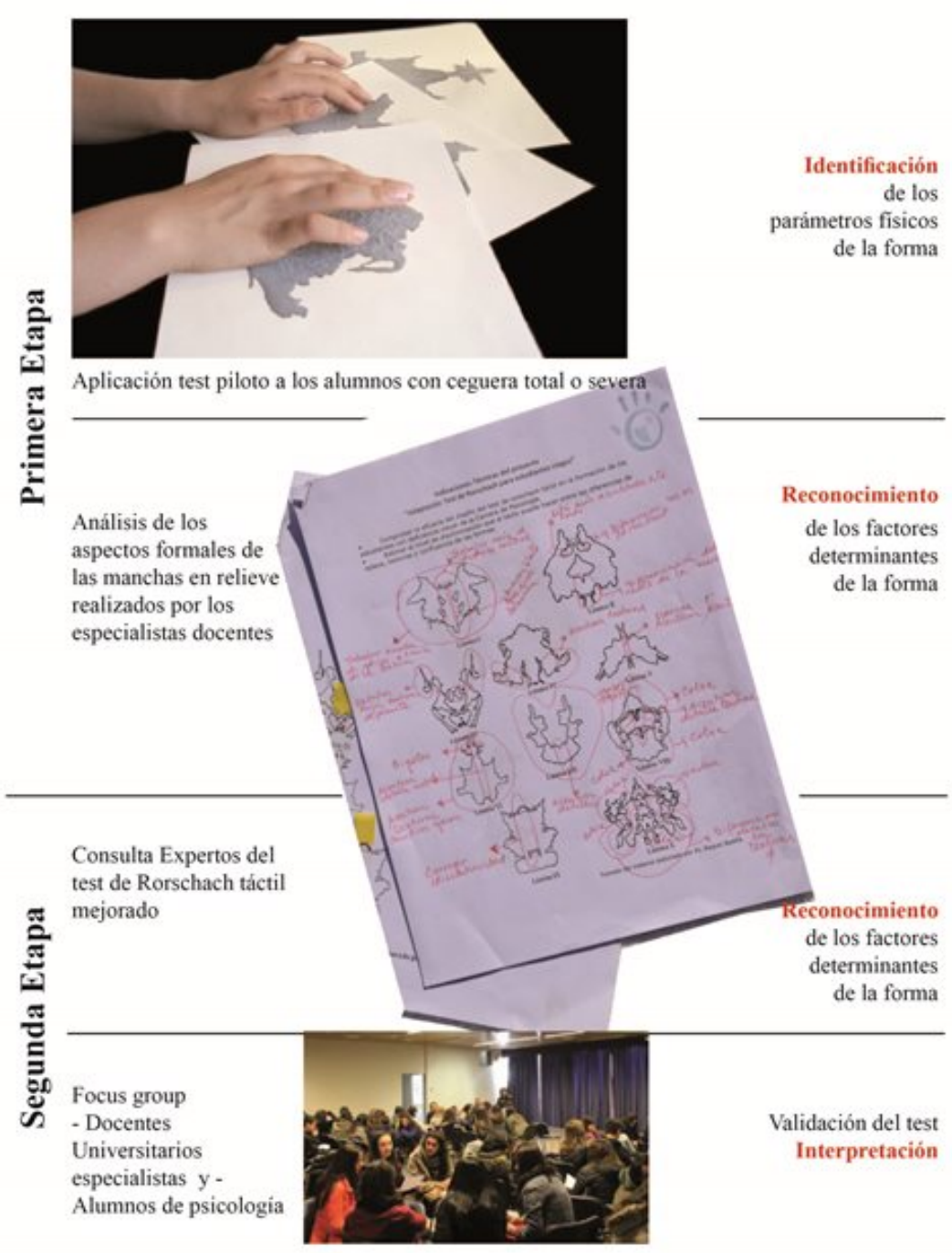

FIGURA 4

Representación del proceso de validación del test de Rorschach táctil en dos etapas Fuente: fotografías Pilar Correa

\section{Resultados}

Los resultados obtenidos se refieren al análisis de las posibilidades de un sistema comunicacional basado en la representación gráfica espacial, en el cual se proponen conexiones entre las partes componentes y el todo de cada lámina, a través de la recogida de datos sensoriales de contacto y de movimiento. El procesamiento de la información es guiado por los datos sensoriales, o de abajo-arriba, en los términos enunciados por Lindsay y Norman (1976). En este caso, dicho procesamiento es conducido especialmente por la captación de información estimular táctil y motora, elaborada a través de sucesivas etapas de reconocimiento y de relación de sus componentes, con el objetivo de lograr la representación mental del estímulo en su totalidad para su identificación. De esta forma se puede alcanzar la comprensión global de la lámina, a partir del reconocimiento de los detalles y su ubicación espacial.

Por las características del sujeto perceptor, se debe recalcar que el valor de este trabajo está en presentar una semiótica sustituyente. En este tipo de semiótica, la información visoespacial de una determinada forma 
(mancha), proviene de sus cualidades topológicas relacionadas con los marcadores de lugar del objeto, lo que genera un adecuado nivel de precisión de la forma que permite al interpretante ciego suplir una carencia.

Resumiendo, el primer resultado que se debe presentar es la síntesis de la caracterización del modelo que se llegó a establecer, desde una perspectiva semiótica, para los cualisignos icónicos táctiles del test de Rorschach, generando una construcción dinámica de las nueve relaciones que los constituyen, sobre la propuesta del esquema peirceano. Dicha síntesis se representa en la tabla 3.

TABLA 3

Propuesta semiótica para el test de Rorschach táctil

\begin{tabular}{|c|c|c|c|c|}
\hline \multirow{3}{*}{$\begin{array}{l}\text { (Algo) } \\
\text { Propuesta de } \\
\text { percepción } \\
\text { táctil del test de } \\
\text { Rorschach }\end{array}$} & $\begin{array}{l}\text { I } \\
\text { (en alguna } \\
\text { relación) } \\
\text { CONSIDERADA } \\
\text { COMO }\end{array}$ & $\begin{array}{l}1 \\
\text { Entidades } \\
\text { constitutivas: } \\
\text { CUALISIGNOS } \\
\text { Las manchas están } \\
\text { configuradas por } \\
\text { formas y texturas. } \\
\text { Borde, contorno } \\
\text { limite, áreas }\end{array}$ & $\begin{array}{l}2 \\
\text { IMAGEN } \\
\text { TÁCTIL } \\
\text { PLÁSTICA } \\
\text { Imagen no } \\
\text { figurativa, de } \\
\text { formas vagas, } \\
\text { centrada, y con } \\
\text { un eje de simetria } \\
\text { bilateral }\end{array}$ & $\begin{array}{l}3 \\
\text { Selección perceptual en } \\
\text { sistemas posibles de: } \\
\text { El observador percibe a } \\
\text { través de diferencias de } \\
\text { nivel formas espaciales } \\
\text { delimitadas, contornos, } \\
\text { texturas. } \\
\text { IDENTIFICACIÓN }\end{array}$ \\
\hline & $\begin{array}{l}\text { II } \\
\text { (por algo) } \\
\text { DESTINADA } \\
\text { A LA }\end{array}$ & $\begin{array}{l}4 \\
\text { Componentes } \\
\text { analítico- } \\
\text { constructivos: } \\
\text { QUALIA } \\
\text { El perceptor } \\
\text { ciego no cuenta } \\
\text { con experiencias } \\
\text { sensoriales previas } \\
\text { con este tipo de } \\
\text { fenómenos. Por lo } \\
\text { que el espectador } \\
\text { no dispone en su } \\
\text { memoria semántica } \\
\text { una experiencia } \\
\text { perceptual- } \\
\text { emocional afin. }\end{array}$ & $\begin{array}{l}\text { ATRACTOR } \\
\text { ABSTRACTIVO } \\
\text { Detalles formales } \\
\text { Disposición } \\
\text { espacial } \\
\text { Orientación, } \\
\text { Ejes de rotación } \\
\text { Tamaño } \\
\text { Ejes de simetria }\end{array}$ & $\begin{array}{l}6 \\
\text { Agrupamientos hacia: } \\
\text { El interior } \\
\text { El exterior } \\
\text { El proceso de la } \\
\text { información se realiza a } \\
\text { partir de los detalles y se } \\
\text { requiere } \\
\text { por el modo aperceptivo } \\
\text { identificar figura y fondo } \\
\text { y sus partes internas } \\
\text { (detalles) como la } \\
\text { relación con la totalidad } \\
\text { del fenómeno a percibir. } \\
\text { RECONOCIMIENTO }\end{array}$ \\
\hline & $\begin{array}{l}\text { III } \\
\text { (para alguien) } \\
\text { PARA SU } \\
\text { VALORACIÓN }\end{array}$ & $\begin{array}{l}7 \\
\text { Actualización del } \\
\text { efecto de sentido. } \\
\text { Interpretación de } \\
\text { manchas en relieve } \\
\text { como una unidad } \\
\text { en plano general o } \\
\text { de detalles } \\
\text { Espacios en } \\
\text { blanco; fondo, } \\
\text { interespacios. } \\
\text { Secuencia de } \\
\text { manchas en relieve } \\
\text { con una secuencia } \\
\text { determinada. }\end{array}$ & $\begin{array}{l}8 \\
\text { MOSTRACIÓN: } \\
\text { de carencia } \\
\text { al tratarse de un } \\
\text { interpretante con } \\
\text { ceguera no hay } \\
\text { preexistencia,en } \\
\text { su memoria } \\
\text { semántica, de un } \\
\text { atractor abstractivo } \\
\text { o sensación } \\
\text { o experiencia } \\
\text { perceptual similar. }\end{array}$ & $\begin{array}{l}9 \\
\text { Interrelación posible: } \\
\text { La interpretación puede } \\
\text { ser: } \\
\text { Respuestas globales } \\
\text { Respuestas a detalles } \\
\text { Detalles Grandes } \\
\text { Detalles Pequeños } \\
\text { Detalles en Blanco } \\
\text { Secuencia }\end{array}$ \\
\hline
\end{tabular}

Fuente: elaboración propia

A partir de las experiencias sensoriales primarias de los perceptores con ceguera, que fueron evocadas directamente por la estimulación del tacto y del movimiento al recorrer las superficies en relieve de las láminas del test, se obtuvieron los parámetros de discriminación de las cualidades morfológicas de cada una de las 
manchas. Se identificaron los rasgos gráficos de cada una de ellas requeridos para conformar los atractores de cada una de sus representaciones táctiles, resultantes de la experiencia de los especialistas psiconometristas.

Se pesquisaron las carencias que presentan las representaciones táctiles de las manchas para ser interpretadas como signos portadores de significados codificados, que, entre sus posibles lecturas, consideran la orientación de cada una y su orden de presentación. Se obtuvieron las tipologías básicas de la materia prima representación gráfica táctil y sus marcadores de lugar-, para promover las operaciones cognitivas del perceptor ciego a través de la unicidad y suficiencia de la batería sometida a validación. Se presenta una síntesis de estos logros en las siguientes (figuras 5, 6 y 7 ).

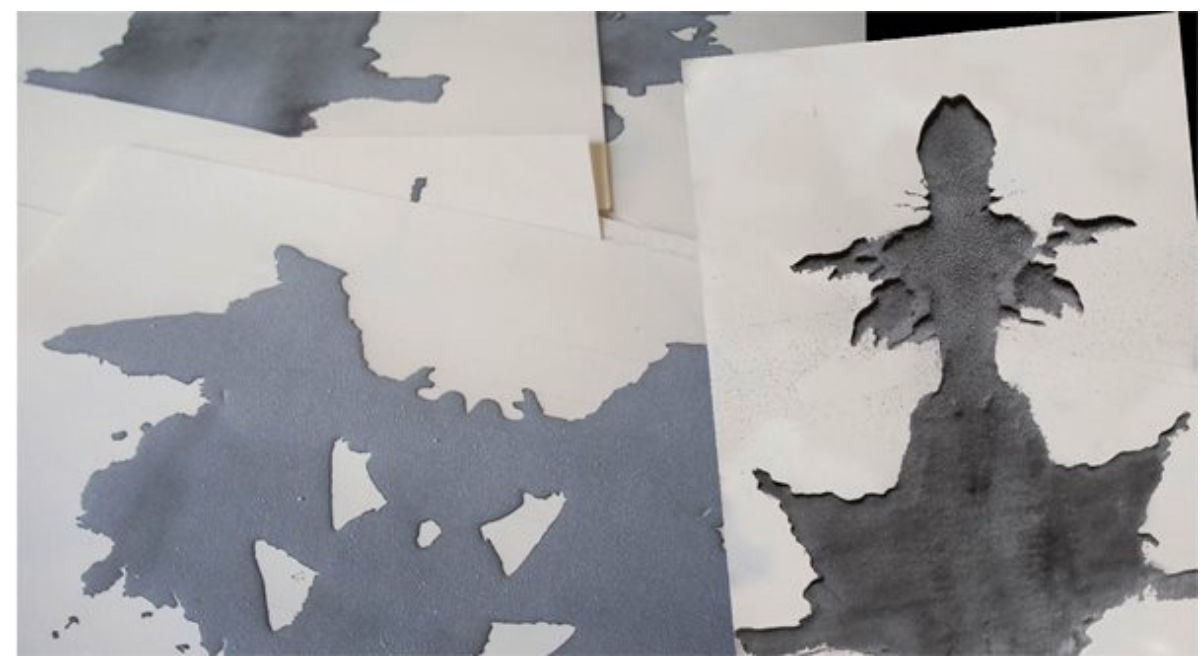

FIGURA 5

Láminas test de Roschach exploratorio

Nota. Se reforzaron todos los bordes de la envoltura de las manchas de modo de optimizar el reconocimiento; se aumentaron las diferencias de rugosidad (brillo) de las superficies, de modo de poder diferenciar al tacto mejor sus diferencias y se ampliaron los tamaños de las superficies tangibles de la imagen de modo que la mano pueda acceder con más dominio a los detalles. Fuente: fotografía Pilar Correa

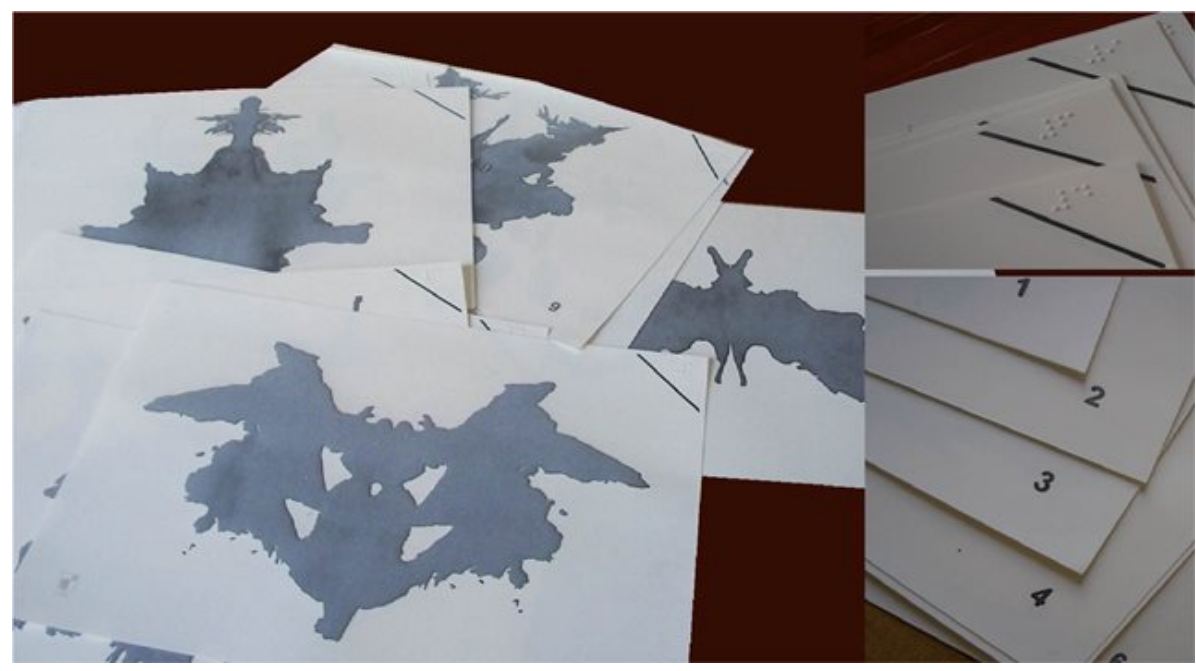

FIGURA 6

Láminas test de Rorschach táctil mejorado

Nota. Los aportes en esta etapa de la validación se dieron en dos planos, uno con las coherencias internas de las formas, sus atractores, haciéndose énfasis en sus componentes analíticos. El otro plano de análisis se enfocó en los aspectos constructivos de posición, indicadores de ligar que informan sobre la orientación y secuencia (numeración) de las láminas. 


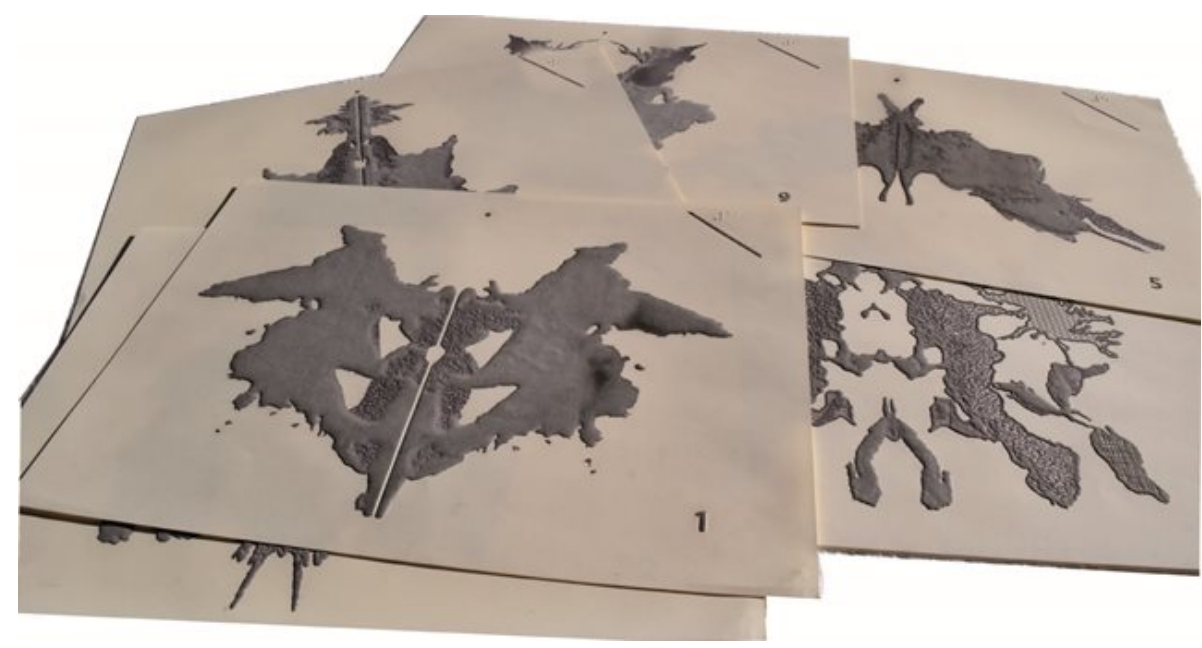

FIGURA 7

Láminas test de Rorschach táctil validado

Nota. La variable color cromático fue un referente que se tuvo que volver a considerar dado que, en la interpretación psicológica es un determinante importante y hay tabuladas respuestas específicas por lo que se implementaron texturas diferentes según las necesidades detectadas de casa mancha. Se hicieron ajustes en sectores de las manchas de modo de resguardar la localización de los detalles y sumó a los indicadores de lugar, el eje de simetría. Fuente: fotografía Pilar Correa

Finalmente presentamos el modelo semiótico resultante para los cualisignos icónicos, que demostró su eficacia interpretativa, para que se pueda constituir en una batería táctil que permita la aplicación del test de Rorschach por un profesional con ceguera. Este modelo se representa en la figura 8. 


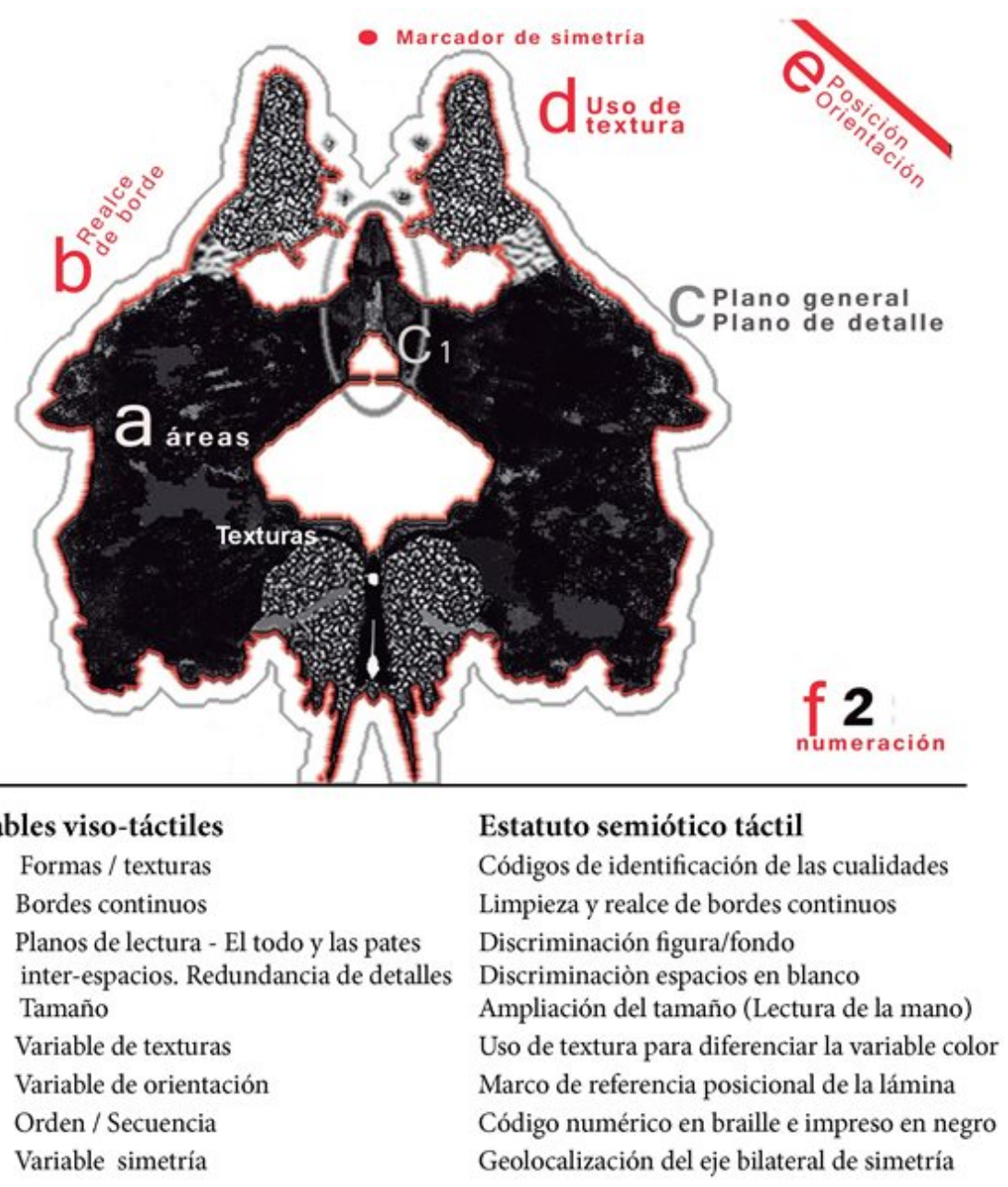

FIGURA 8

Modelo de diseño de las láminas del test de Rorschach táctil

Fuente: elaboración propia

\section{Conclusiones}

Se pudo reconocer que los cualisignos icónicos pueden aspirar a una expresión táctil que los haga visibles a la mano. Sus cualidades representativas los dotan de sentido para ser parte de un modelo semiótico con características propias. Es factible hablar de modelo semiótico sustituyente de test de Rorschach, al proponer una existencia corpórea que lo faculta como una mediación instrumental, para ser parte de los recursos de aprendizaje de los estudiantes con ceguera.

El modelo semiótico sustituyente demostró su eficacia interpretativa, al proporcionar las representaciones de los signos y sus coordenadas como atributos tangibles a un perceptor carente de atractor mnemo\#nico y, a través de esta experiencia, conformar una primera representación mental de estas manchas. A partir de estas primeras experiencias sensoriales, con este tipo de signos, cada estudiante en situación de discapacidad puede constituir los qualia como recursos semióticos privados, con los cuales enfrentar la lectura de los atractores del signo, en su totalidad o por detalles, que apoyen la precisión de la localización y del criterio de codificación.

La técnica de exploración y los recursos morfológicos utilizados por los estudiantes con ceguera total o severa se asemejan a los empleados para identificar e interpretar mapas táctiles. Realizan un mapeo de las superficies texturadas sobre un soporte con referencias de lugar y posición. En este aspecto, se confirma, en relación con el proceso de reconocimiento, de las formas hápticas, que es determinante el recorrido de la mano 
en movimiento sobre la línea continua que la delimita, permitiéndole a esta generar los atractores del objeto. Considerando este alcance, se puede seguir profundizando en la relación movimiento y conformación de la imagen mental a través del tacto, ya que esta característica es también responsable del acto de ver con luz.

\section{Discusión}

Estas evidencias se podrían continuar profundizando para promover las capacidades del tacto activo como forma de enriquecer y diversificar los procesos educativos. En estudios en los cuales se han analizado simultáneamente estas dos formas de recoger información, visual y táctil, destacan los notables paralelismos que se dan en el procesamiento de patrones espacio-temporales a través del movimiento visual y/o táctil (Pei y Bensmaia, 2014). En los aspectos más didácticos, en la actualidad, hay una gran variedad de investigaciones en las cuales se evidencia la importancia del movimiento corporal en el fenómeno del conocer; su taxonomía es amplia e involucra distintos niveles. Se conoce como aprendizaje encarnado, siendo uno de los enfoques teóricos más influyentes la cognición encarnada (CE) (Skulmowski y Rey, 2018, p. 1). De este modo, se podría ampliar la oferta educativa y reducir la problemática de la inclusión desde una perspectiva sociocultural, en la cual, desde el diseño, se pueden presentar aportes que eliminen, o por lo menos reduzcan, las barreras en el acceso a un tipo de información sensorial.

Otros estudios que se vislumbran como posibilidades con base en esta propuesta, tienen que ver con precisar de qué modo las representaciones táctiles podrían cumplir un rol configurador de la información gráficovisual (infografías), para que las personas con ceguera puedan construir, en este caso con énfasis en lo perceptivo, sus respectivas semiosis y sus qualia, empleando la información espacial y sus relaciones con el entorno.

\section{Referencias}

Ballesteros, S., Bardisa, D., y Reales, J. (2005). The haptic test battery: A new instrument to test tactual abilities in blind and visually impaired and sighted children. The British Journal of Visual Impairment, 23(1). https://doi.org/1 $0.1177 / 0264619605051717$

Bense, M., y Walther, E. (1975). La semiótica. Guía alfabética. Barcelona: Anagrama.

Chiny, J., Salas, K., y Vargas, M. (2008). Accesibilidad para ingresar a la educación superior: desafíos y logros desde el enfoque de la diversidad. Revista Electrónica Educare, 12(1), 71-82. Recuperado de http://www.redalyc.org/pd f/1941/194114582011.pdf

Claudet, P., Theurel, A., Wit, A., Hatwell, Y., Gentaz, E. (2013). Tactile picture recognition by early blind children: The effect of illustration technique. Journal of Experimental Psychology: Applied, 19(3), 233-240. https:// doi.org/10.1037/a0034255

Correa Silva, M. P. (2011). Imágenes que podemos tocar. Santiago de Chile: Editorial Universidad Tecnológica Metropolitana.

Edman, P. (1992). Tactile graphics. Nueva York: American Foundation for the Blind.

Eriksson, Y. (1999, agosto). How to make tactile pictures understandable to the blind reader. Trabajo presentado en el 65th IFLA Council y la General Conference, Bangkok, Thailand.

Focillon, H. (2010). La vida de las formas y Elogio de la mano (trad. F. Zamora). México: Editorial Universidad Nacional Autónoma de México.

Gibson, J. (1974). La percepción del mundo visual. Buenos Aires: Ediciones Infinito.

Grupo $\mu$. (1993). Tratado del signo visual. Para una retórica de la imagen. Madrid: Cátedra.

Heller, A. (ed.). (2000). Touch, representation, and blindness. Nueva York: Oxford University Press. 
Jay, M. (2007). Ojos abatidos. La denigración de la visión en elpensamiento francés del siglo XX (trad. F. Lo\#pez). Madrid: Akal Ediciones S. A.

Katz, D. (1930). El mundo de las sensaciones táctiles. Madrid: Revista de Occidente.

Kennedy, J. M. (2005). Lo tangible y lo visible en los dibujos que realizan las personas ciegas. Integración: Revista sobre Ceguera y Deficiencia Visual, 44, 7-12. Recuperado de https://www.once.es/dejanos-ayudarte/la-discapacidad-v isual/revista-integracion/2005-integracion-44-46/sumario-del-numero-44-de-la-revista-integracion

Lindsay, P., y Norman, D. (1976). Procesamiento de información humana. Una introducción a la psicología. Percepción y reconocimiento de formas (trads. J. Seoane y C. García Trevijano). Madrid: Editorial Tecnos.

Lissi, M., Zuzulich, S., Hojas, A., Achiardi, C., Salinas, M., y Vásquez, A. (2013). En el camino hacia la educación superior inclusiva en Chile: fundamentos y adecuaciones curriculares para estudiantes con discapacidad sensorial o motora. Santiago: Pontificia Universidad Católica de Chile, Dirección de Asuntos Estudiantiles, Salud Estudiantil, Programa para la Inclusión de Alumnos con Necesidades Especiales, PIANE-UC. Recuperado de http://piane. uc.cl/images/educacion_superior_inclusiva_en_chile.pdf

Magariños de Morentin, J. (2008). La semiótica de los bordes. Córdoba: Comunicarte.

Marr, D. (1985). Vision: A computational investigation into the human representation and processing of visual information (trad. M. del Amo). Madrid: Alianza.

Maturana, H., y Varela, F. (1984). El árbol del conocimiento: las bases biológicas del entendimiento humano. Santiago de Chile: Lumen Universitaria.

Moriña Díez, A., y Cotán, A. (2011). La perspectiva del alumnado con discapacidad sobre la universidad. Quaderns Digitals. Revista de Nuevas Tecnologías y Sociedad, 69. Recuperado de http://www.quadernsdigitals.net/dato s/hemeroteca/r_75/nr_817/a_11037/11037.html

Moriña Díez, A., y Perera Rodríguez, V. H. (2016). ¿Educacio\#n inclusiva en la ensen\#anza superior?: el caso del alumnado con discapacidad. Revista Ibero-Americana de Estudos em Educação, 10, 599-614. https://doi.org/10 .21723

Moswela, E., y Mukhopadhyay, S. (2011). Asking for too much? The voices of student with disabilities in Botswana. Disability \& Society, 26(3), 307-319. https://doi.org/10.1080/09687599.2011.560414

Nielsen, J., y Loranger, H. (2006). Usabilidad. Prioridad en el diseño web. Madrid: Anaya.

Pei, Y. C., y Bensmaia, S. J. (2014). The neural basis of tactile motion perception. Journal of Neurophysiology, 112(12), 3023-3032. https://doi.org/10.1152/jn.00391.2014

Peirce, C. S. (1974). La ciencia de la semio\#tica. Buenos Aires: Ediciones Nueva Visión.

Revèsz, G. (1950). Psychologie and art of the blind. Nueva York: Logmans, Grennan Co.

Rosa, A. (1980). Mental images and cognitive development in people totally blind from birth. Estudios de Psicología, 1(4), 24-66. https://doi.org/10.1080/02109395.1980.10821241

Salinas Alarcón, M., Lissi, M. -R., Medrano Polizzi, D., Zuzulich Pavez, M. -S., y Hojas Loret, A. -M. (2013). La inclusión en la educación superior: desde la voz de estudiantes chilenos con discapacidad. Revista Iberoamericana de Educación, 63, 77-98. https://doi.org/10.35362/rie630502

Skulmowski, A., y Rey, G. D. (2018). Embodied learning: Introducing a taxonomy based on bodily engagement and task integration. Cognitive Research: Principles and Implications, 3(6). https://doi.org/10.1186/s41235-018-00 92-9

Vanoni, E. (2006). Cartografía de la discapacidad. Cordova: Brujas.

Vygotski, L. S. (2000). El desarrollo de los procesos psicológicos superiores (trad. S. Furió). Barcelona: Crítica.

\section{Notas}

* Artículo de investigación científica.Estudio realizado con fondos internos de la Universidad Tecnológica Metropolitana. 
Cómo citar este artículo: Correa Silva, M. del P. (2019). Una interpretación del tacto activo a partir del estudio morfológico del test de Rorschach y su adaptación desde la perspectiva de la educación inclusiva. Signo y Pensamiento, 38(75). https://doi.org/10.11144/Javeriana.syp38-75.itae 